\title{
0320 VANCOUVER CHARTER: BRINGING SKI AND SNOWBOARD HELMET LEGISLATION TO CANADA
}

P Fuselli*, B Hagel, R Stanwick Correspondence: Safe Kids Canada/The Hospital for Sick Children, 180 Dundas Street West, Suite 2105, Toronto, Ontario, M5G 1Z8, Canada

\subsection{6/ip.2010.029215.320}

The Vancouver Charter on Skiing Safety is based on skiing and snowboarding safety and the Turin Charter (approved in the context of the 2006 Turin Winter Olympic Games) and was brought to Canada by Safe Kids Canada. Originally prepared by a panel of experts and specialists delegated by European Governments who worked under the coordination of TOROC (Turin Organizing Committee), BE.PRA.S.A. (a project co-financed by the European Commission and the health authority of the Italian region of Veneto) and the Italian National Health Institute, the aim of the Charter is to promote a safe, healthy and active sporting and recreational culture, and to make its principles visible to the public, citizens and institutions. Over 30 international, national, provincial and municipal organisations have endorsed the Charter to date. The Charter was introduced at a Helmet Forum in November 2009 in Vancouver and featured experts such as Dr Charles Tator, Dr Richard Stanwick, Dr Brent Hagel and Mr Matt Herman. The forum was attended by injury prevention experts, ski/snowboard industry representatives and media and resulted in extensive national media coverage of the issue, especially the diversity of opinions and debates it has created. This presentation will show Safe Kids Canada's experience of how the Charter can be leveraged by other countries, review the challenges and successes, present our knowledge translation 'recipe for success' and update the audience on activities to date. 